\title{
ANALISIS DAN RANCANG BANGUN SISTEM INFORMASI PERAMALAN TINGKAT PENJUALAN PRODUK TELKOM
}

\section{(Studi Kasus PT TELKOM, Tbk Blitar)}

\author{
Excellina $^{1}$, Yan Watequlis Syaifudin ${ }^{2}$, Mungki Astiningrum ${ }^{3}$ \\ 1,2 Jurusan Teknik Elektro, Program Studi Teknik Informatika, Politeknik Negeri Malang \\ 1 excellina12@gmail.com
}

\begin{abstract}
Abstrak
Excellina, 2014, Analisis dan Rancang Bangun Sistem Informasi Peramalan Tingkat Penjualan Produk Telkom (Studi Kasus PT. Telkom, Tbk Blitar), Skripsi, Program Studi Teknik Informatika, Jurusan Teknik Elektro, Politeknik Negeri Malang. Pemnbimbing: (1) Yan Watequlis Syaifudin, S.T., MMT (2) Mungki Astiningrum, S.T., M.Kom

PT. Telkom sebagai salah satu perusahaan telekomunikasi terbesar di Indonesia yang selalu berusaha meningkatkan dan menjaga kualitas layanannya mencoba memasuki potensi pasar dari pengguna internet dengan menyediakan layanan akses internet lewat produknya TDSL (Tube Data Sheet Locator) dan Telepon. Agar dapat bersaing dengan perusahaan lain, salah satu cara yang dapat dilakukan adalah mendapatkan sumber informasi yang akurat untuk membuat rencana di masa depan atau peramalan. Tujuan dari pembuatan sistem informasi ini adalah mengadopsi analisa forecasting secara manual ke dalam sebuah sistem informasi agar lebih praktis, dengan pemrograman php dan MySql sebagai databasenya. Selain itu, digunakan Double exponential smoothing, Moving average dan Least Squares sebagai metodenya sebagai dasar untuk pengambilan keputusan dalam jangka waktu tertentu. Setelah dilakukan observasi pada PT. Telkom, Tbk Blitar, didapat hasil yaitu data historis penjualan produk TDSL dan Telepon pada tahun 2008-2012 untuk dianalisa. Dari ketiga metode yang dipakai pada sistem ini kemudian dihitung forecast error-nya dengan menggunakan metode Mean Error. Dari analisa yang telah dilakukan, dapat disimpulkan bahwa sistem peramalan ini dapat digunakan untuk mengetahui prediksi/peramalan penjualan produk Telkom pada masa mendatang, sehingga dapat membantu PT. Telkom, Tbk Blitar untuk menentukan pengambilan kebijakan dalam penjualan kedepannya.
\end{abstract}

Kata Kunci : Peramalan, Moving Average, Double Exponential Smoothing, Least Square

\section{PENDAHULUAN}

Komunikasi dan internet merupakan hal yang sangat penting dalam kehidupan manusia saat ini. Komunikasi telah menjadi sesuatu yang sangat vital dan telah menjadi kebutuhan bagi kita untuk saling terhubung satu sama lain. Salah satu sarana komunikasi adalah telepon. Sama halnya dengan internet, yang merupakan salah satu sumber informasi dari media elektronik. Keunggulan dari internet adalah sumber informasi yang di dapat lebih beragam, biaya yang dikeluarkan untuk mendapatkan informasi lebih murah, dan lebih cepat dalam memperolehnya. Informasi diperlukan sebagai salah satu sumber daya dalam merealisasikan suatu rencana untuk mendukung tercapainya target kegiatan yang berhubungan dalam pengambilan keputusan. Informasi yang mengandung kebenaran dan keakuratan diperlukan sebagai syarat untuk menghasilkan keputusan yang benar yang berdampak pada hasil yang diharapkan.
PT. Telkom sebagai salah satu perusahaan telekomunikasi terbesar di Indonesia yang selalu berusaha meningkatkan dan menjaga kualitas layanannya mencoba memasuki potensi pasar dari pengguna telepon dan internet dengan menyediakan layanan akses internet dengan berbagai macam produk maupun layanan telepon. Agar dapat bersaing dengan perusahaan lain, salah satu cara yang dapat dilakukan adalah mendapatkan sumber informasi yang akurat untuk membuat rencana dimasa depan atau peramalan (forecasting).

Berdasarkan hasil observasi dan wawancara yang telah dilaksanakan kepada manajer operasional PT. Tekom, Tbk Blitar, selama ini masih menerapkan peramalan untuk rencana peningkatan penjualan dalam rencana target laba pada waktu mendatang berupa biaya (Rupiah) dan dengan menargetkan untuk peningkatan hasil laba untuk selalu meningkat sekian persen (\%). Untuk menyelaraskan hasil peramalan dalam bentuk 
seperti demikian, perlu dibangun suatu sistem peramalan yang lebih detail untuk mengetahui tingkat penjualan pada masa mendatang sesuai dengan produk sehingga didapatkan hasil yang optimal setiap peramalan dan dapat menjadi acuan untuk menentukan keputusan yang akan diambil serta mengetahui layanan produk mana yang harus ditingkatkan lagi agar membuat pelanggan tetap memilih produk Telkom sebagai pilihan yang tepat.

Sistem peramalan ini dibuat agar dapat meminimumkan pengaruh ketidakpastian terhadap masalah dan hambatan yang akan terjadi dimasa depan. Masalah dan hambatan yang muncul dapat berupa apakah produk di PT. Tekom, Tbk Blitar masih diminati oleh pasar, atau bagaimanakah kondisi pasar pada masa mendatang, mengalami peningkatan atau penurunan. Dengan adanya sistem peramalan ini, masalah dan hambatan tersebut dapat diprediksi.

\section{METODE}

\subsection{Use Case}

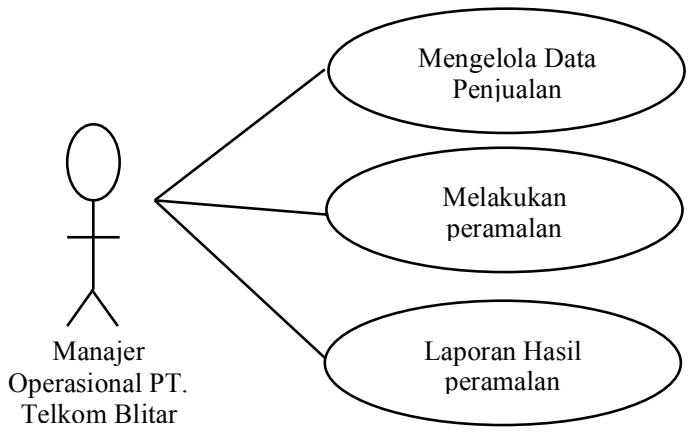

Gambar 2.1 Use Case

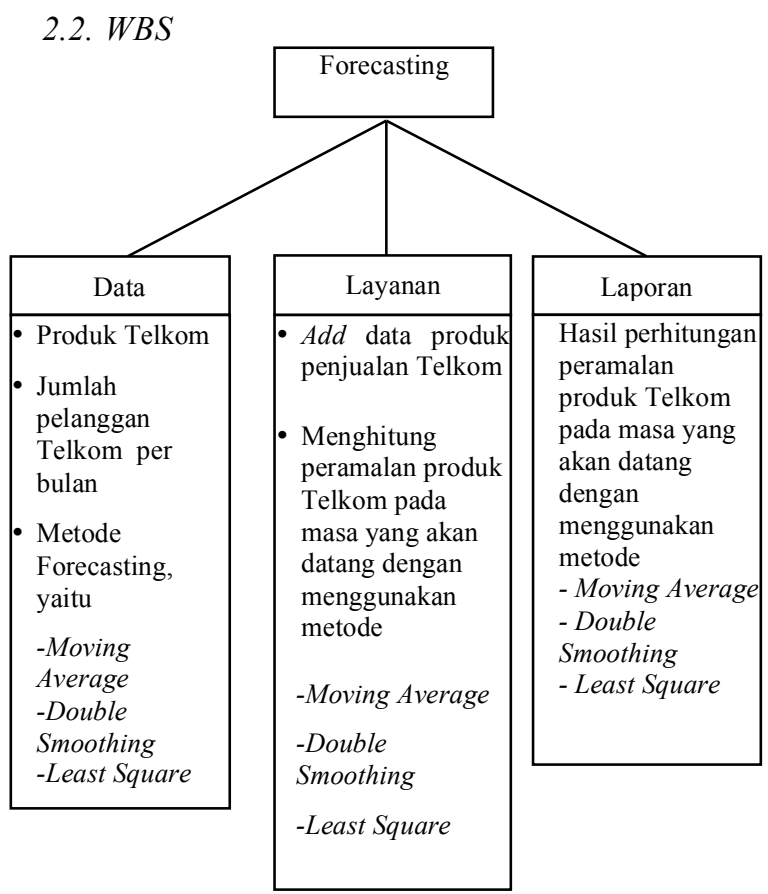

Gambar 2.2 WBS

\subsection{Moving Averages}

Dalam melakukan suatu peramalan bisnis atau business forecasting, ada beberapa metode yang dipakai untuk membuat suatu peramalan, salah satu metode yang dipakai adalah metode single moving average, atau metode rata - rata bergerak tunggal, metode ini digunakan sebagai pemulusan data yang tidak beraturan. Secara manual metode single moving average dapat dicari dengan rumus:

$$
\mathrm{S}_{\mathrm{t}-1}=\frac{X t+X t-1+\cdots . . X t-n+1}{n}
$$

Dimana :

$\mathrm{S}_{\mathrm{t}+1}=$ Forecasting untuk period ke

$\mathrm{t}+1$

$\mathrm{X}_{\mathrm{t}}=$ Data pada periode $t$

$\mathrm{N} \quad=$ Jangka waktu Moving Averages

\subsection{Double Exponential Smoothing}

Pendapat Makridakis, Wheelwright \& McGee (1998:117) yang menyebutkan bahwa :

"Metode ini merupakan metode forecast yangdikemukakan olehBrowndengan menggunakan persamaan kuadrat". Di dalam metode double exponential smoothing brown dilakukan proses smoothing dua kali, yaitu menghitung nilai pemulusan eksponensial tunggal dan nilai pemulusan eksponential ganda. Setelah kedua proses dilakukan kemudian menghitung nilai Forecast dengan rumus

$$
F_{t+m}=a_{t}+b_{t m}
$$

\subsection{Least Squares}

Metode Least Square digunakan untuk analisis time series adalah Metode Garis Linier Secara Bebas (Free Hand Method), Metode Setengah Rata-Rata (Semi Average Method), Metode Rata-Rata Bergerak (Moving Average Method) dan Metode Kuadrat Terkecil (Least Square Method). Dalam hal ini akan lebih dikhususkan untuk membahas analisis time series dengan metode kuadrat terkecil yang dibagi dalam dua kasus, yaitu kasus data genap dan kasus data ganjil. Secara umum persamaan garis linier dari analisis time series adalah :

$$
\mathrm{Y}=\mathrm{a}+\mathrm{b} \mathrm{X} \text {. }
$$

\subsection{Data produk PT Telkom Blitar}

Berikut ini adalah statistik data penjualan produk PT. Telkom Blitar dari tahun $2008-$ tahun 2012. Pola data seperti ini disebut dengan pola data Siklis. Menurut Nugroho J.Setiadi, SE., MM., data siklis adalah nilai data yang dipengaruhi oleh fluktuasi 
ekonomi yang panjang seperti dihubungkan dengan data siklis bisnis dan lain-lain. (2003, hal: 27)

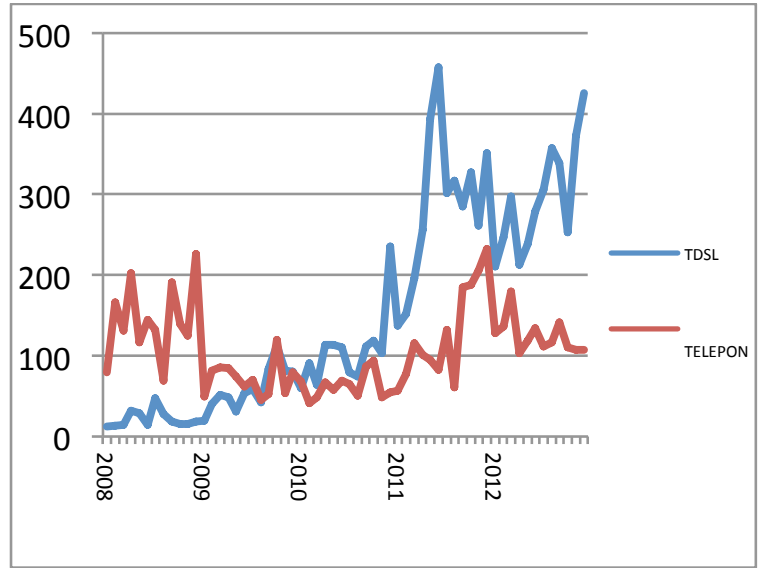

Gambar 2.3 Statistik penjualan produk PT. Telkom periode 2008 - 2012

\section{HASIL}

Sistem informasi peramalan produk Telkom ini akan digunakan di PT. Telkom Tbk, Blitar sebagai aplikasi untuk membantu meramalkan produk Telkom untuk masa mendatang agar tepat dan akurat dalam pengambilan keputusan untuk meningkatkan pelayanan produk Telkom. User yang menggunakan aplikasi ini adalah manager operasional dari PT. Telkom Tbk, Blitar.

3.1 Tampilan aplikasi peramalan Halaman Login

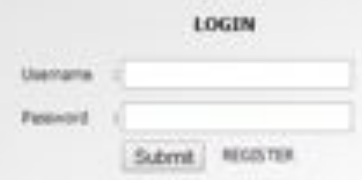

Gambar 3.1 Halaman Login

Halaman Produk

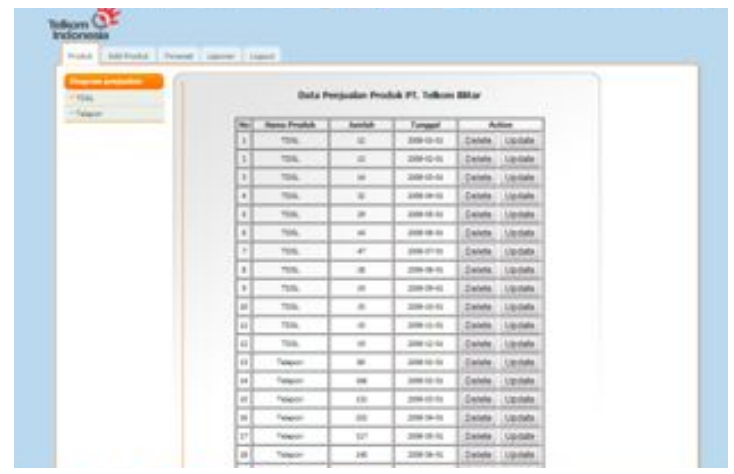

Gambar 3.2 Halaman Produk
Halaman Add Produk

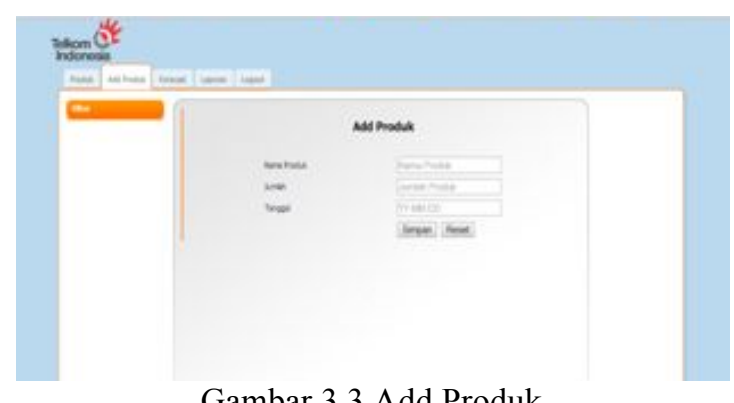

Gambar 3.3 Add Produk

Halaman Forecast

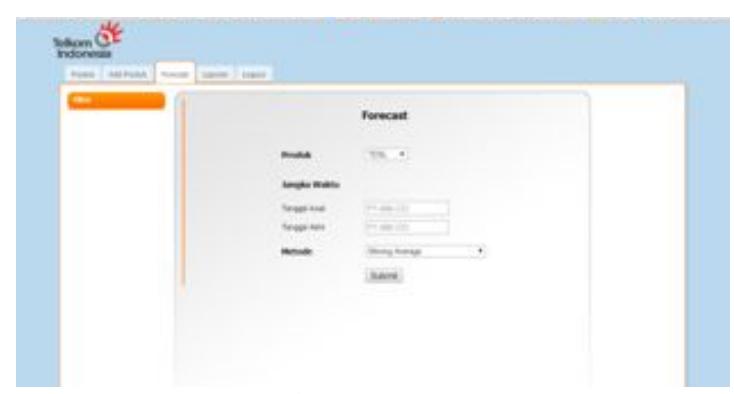

Gambar 3.4 Forecast

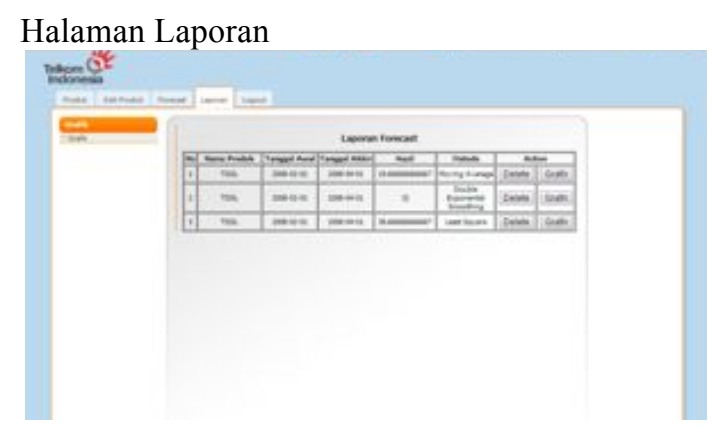

Gambar 3.5 Laporan

\section{PEMBAHASAN}

Dengan menggunakan metode Moving Averages, Double Exponrntial Smoothing, dan Least Squares, dapat dihitung untuk meramalkan produk di masa mendatang. Data untuk uji coba diambil dari periode tahun 2008-2012.

\begin{tabular}{ccc} 
Periode & TDSL & TELEPON \\
\hline $1 / 1 / 2008$ & 12 & 80 \\
$1 / 2 / 2008$ & 13 & 166 \\
$1 / 3 / 2008$ & 14 & 131 \\
$1 / 4 / 2008$ & 32 & 202 \\
$1 / 5 / 2008$ & 29 & 117
\end{tabular}




\begin{tabular}{|c|c|c|}
\hline $1 / 6 / 2008$ & 14 & 145 \\
\hline $1 / 7 / 2008$ & 47 & 132 \\
\hline $1 / 8 / 2008$ & 28 & 69 \\
\hline $1 / 9 / 2008$ & 19 & 191 \\
\hline $1 / 10 / 2008$ & 15 & 139 \\
\hline $1 / 11 / 2008$ & 15 & 125 \\
\hline $1 / 12 / 2008$ & 19 & 226 \\
\hline $1 / 1 / 2009$ & 20 & 50 \\
\hline $1 / 2 / 2009$ & 40 & 82 \\
\hline $1 / 3 / 2009$ & 52 & 86 \\
\hline $1 / 4 / 2009$ & 48 & 85 \\
\hline $1 / 5 / 2009$ & 31 & 74 \\
\hline $1 / 6 / 2009$ & 54 & 62 \\
\hline $1 / 7 / 2009$ & 59 & 70 \\
\hline $1 / 8 / 2009$ & 42 & 45 \\
\hline $1 / 9 / 2009$ & 84 & 53 \\
\hline $1 / 10 / 2009$ & 82 & 120 \\
\hline $1 / 11 / 2009$ & 81 & 54 \\
\hline $1 / 12 / 2009$ & 81 & 80 \\
\hline Periode & TDSL & TELEPON \\
\hline $1 / 1 / 2010$ & 60 & 68 \\
\hline $1 / 2 / 2010$ & 91 & 41 \\
\hline $1 / 3 / 2010$ & 64 & 48 \\
\hline $1 / 4 / 2010$ & 114 & 67 \\
\hline $1 / 5 / 2010$ & 114 & 58 \\
\hline $1 / 6 / 2010$ & 110 & 69 \\
\hline $1 / 7 / 2010$ & 80 & 65 \\
\hline $1 / 8 / 2010$ & 74 & 51 \\
\hline $1 / 9 / 2010$ & 112 & 87 \\
\hline $1 / 10 / 2010$ & 119 & 94 \\
\hline $1 / 11 / 2010$ & 103 & 49 \\
\hline $1 / 12 / 2010$ & 235 & 55 \\
\hline $1 / 1 / 2011$ & 137 & 57 \\
\hline $1 / 2 / 2011$ & 152 & 77 \\
\hline $1 / 3 / 2011$ & 196 & 116 \\
\hline $1 / 4 / 2011$ & 256 & 101 \\
\hline $1 / 5 / 2011$ & 393 & 95 \\
\hline $1 / 6 / 2011$ & 457 & 83 \\
\hline $1 / 7 / 2011$ & 301 & 132 \\
\hline $1 / 8 / 2011$ & 317 & 61 \\
\hline $1 / 9 / 2011$ & 285 & 185 \\
\hline
\end{tabular}

$\begin{array}{lll}1 / 10 / 2011 & 327 & 188 \\ 1 / 11 / 2011 & 261 & 205 \\ 1 / 12 / 2011 & 351 & 232 \\ 1 / 1 / 2012 & 211 & 128 \\ 1 / 2 / 2012 & 247 & 136 \\ 1 / 3 / 2012 & 297 & 180 \\ 1 / 4 / 2012 & 213 & 103 \\ 1 / 5 / 2012 & 238 & 119 \\ 1 / 6 / 2012 & 279 & 134 \\ 1 / 7 / 2012 & 306 & 111 \\ 1 / 8 / 2012 & 357 & 117 \\ 1 / 9 / 2012 & 339 & 141 \\ 1 / 10 / 2012 & 253 & 110 \\ 1 / 11 / 2012 & 373 & 107 \\ 1 / 12 / 2012 & 425 & 107\end{array}$

Tabel 4.1 Tabel data produk PT Telkom periode tahun 2008

4.1.1. Analisa Metode Moving Averages

Pada pengujian metode Moving Average, penulis melakukan peramalan dengan jangka waktu yang berbeda, yaitu 3 bulan, 4 bulan, dan 5 bulan untuk mengetahui pada jangka waktu yang mana peramalan menunjukkan hasil ME terkecil. Menurut Nugroho J. Setiadi, SE., MM., salah satu sifat khusus dari metode Moving Average adalah semakin panjang jangka waktu perata (Moving Average) akan mengasilkan prakiraan yang semakin halus. Hal ini akan dibuktikan dengan pengujian peramalan produk TDSL dan Telepon menggunakan metode Moving Average. Berikut ini adalah hasil perhitungan rata-rata dari ME dengan range waktu yang berbeda.

\begin{tabular}{|c|c|c|}
\hline $\begin{array}{c}\text { Range } \\
\text { Waktu }\end{array}$ & Produk TDSL & $\begin{array}{c}\text { Produk } \\
\text { Telepon }\end{array}$ \\
\cline { 2 - 3 } & ME & ME \\
\hline 3 bulan & 5.853185 & 1.880296 \\
\hline 4 bulan & 5.44875 & 1.682813 \\
\hline 5 bulan & 4.221714 & 1.603429 \\
\hline
\end{tabular}

Tabel 4.2 Tabel hasil analisa metode Moving Average

\subsubsection{Analisa Metode Double Exponential Smoothing}

Pada Pada pengujian metode Double Exponential Smoothing, penulis melakukan pengujian alpha $(\alpha)$ untuk 
mengetahui dengan menggunakan nilai alpha $(\alpha)$ berapa peramalan yang dilakukan dapat menghasilkan ME yang paling kecil. Pengujian alpha $(\alpha)$ ini dilakukan untuk meminimalisasi penyimpangan nilai forecast error, karena pada metode ini alpha $(\alpha)$ dapat ditentukan secara bebas antara range 0-1. Sehingga pengujian alpha $(\alpha)$ sangat penting, karena nilai apha $(\alpha)$ yang dipilih dapat mempengaruhi hasil permalan. Berikut ini adalah pengujian ME dengan alpha $(\alpha)$ yang berbeda pada peramalan produk TDSL dan Telepon dapat dilihat pada tabel berikut ini.

\begin{tabular}{|c|c|c|c|c|}
\hline Produk & $\alpha=0.3$ & $\alpha=0.4$ & $\alpha=0.5$ & $\alpha=0.6$ \\
\hline TDSL & 15.00229 & 8.489143 & 1.748571 & -4.24914 \\
\hline Telepon & 9.427429 & 5.248 & 1.068571 & -3.11086 \\
\hline
\end{tabular}

Tabel 4.3 Tabel hasil analisa metode

Double Exponential Smoothing

Dari tabel diatas, dapat dilihat perbandingan hasil peramalan yang dihitung dengan apha $(\alpha)$ yang berbeda. Hasil ME terkecil didapat dengan menggunakan alpha $(\alpha)=0.5$ pada perhitungan peramalan produk TDSL maupun Telepon, yaitu nilai ME 1.748571 pada perhitungan peramalan produk TDSL dan 1.068571 pada perhitungan peramalan pada produk Telepon. Sehingga dapat disimpulkan untuk perhitungan peramalan selanjutnya menggunakan alpha $(\alpha)=$ 0.5 untuk meminimalisasi penyimpangan nilai forecast error.

\subsubsection{Metode Least Squares}

Pada pengujian dengan menggunakan metode Least Square ini, akan dilakukan pengujian dari tahun 2008 hingga 2012 sesuai data yang tersedia. Serta perhitungan dilakukan dengan meramalkan produk TDSL dan produk Telepon. Peramalan dilakukan untuk mengetahui seberapa besar forecast error yang terjadi dengan menggunakan rumus Mean Error (ME).

\begin{tabular}{|c|c|}
\hline Produk & ME \\
\hline TDSL & -0.0634286 \\
\hline Telepon & 0.542286 \\
\hline \multicolumn{2}{|c|}{ Tabel 3.3 Tabel uji coba metode } \\
Double Exponential Smoothing
\end{tabular}

Dari kedua tabel diatas, dapat dilihat bahwa nilai ME yang dihasilkan mendekati nol. Hal ini berarti penyimpangan yang dihasilkan dengan menggunakan metode Least Square sangat kecil. Sehingga ketepatan peramalan yang dihasilkan pun sangat akurat.

\section{KESIMPULAN DAN SARAN}

Berdasarkan penelitian yang telah dilakukan oleh penulis pada rancang bangun sistem peramalan tingkat penjualan produk pada PT. Telkom, dengan menggunakan Metode Single Moving Average, Double Exponential Smoothing, dan Least Squares dapat diambil beberapa kesimpulan sebagai berikut:

1. Sistem peramalan ini dapat digunakan untuk mengetahui prediksi/peramalan penjualan produk Telkom pada masa mendatang, sehingga dapat membantu PT. Telkom, Tbk Blitar untuk menentukan pengambilan kebijakan dalam penjualan kedepannya.

2. Pada peramalan menggunakan metode Moving Average, nilai $\mathrm{ME}$ yang dihasilkan pada range waktu 5 bulan paling kecil dibandingkan dengan range waktu 3 bulan dan 4 bulan. Sehingga dapat direkomendasikan, untuk penggunaan metode Moving Average kedepannya dapat menggunakan peramalan dengan range waktu 5 bulan.

3. Semakin panjang range waktu yang digunakan untuk meramal, maka akan mengasilkan peramalan yang semakin halus.

4. Pada peramalan menggunakan metode Double Exponential Smoothing, nilai ME terkecil didapat dengan menggunakan alpha $(\alpha)=0.5$. Untuk perhitungan peramalan selanjutnya, menggunakan alpa $(\alpha)=0.5$ untuk meminimalisasi penyimpangan nilai forecast error.

5. Pada peramalan menggunakan metode Least Square, nilai ME yang dihasilkan mendekati nol. Hal ini berarti penyimpangan yang dihasilkan dengan menggunakan metode Least Square sangat kecil. Sehingga ketepatan peramalan yang dihasilkan pun sangat akurat.

Penelitian ini masih dapat dikembangkan menjadi sistem yang lebih kompleks, tidak hanya terfokus pada peramalan penjualan produk saja. Berikut merupakan beberapa hal yang disarankan untuk pengembangan aplikasi ini, yaitu: 
1. Untuk penelitian selanjutnya, dapat dilakukan penambahan user dan admin sendiri, sehingga sistem dapat digunakan secara global, namun tetap pada kendali admin.

2. Penelitian ini dapat dikembangkan dengan penambahan analisa untuk membandingkan metode yang paling akurat untuk digunakan kedepannya.

\section{DAFTAR RUJUKAN}

1. Setiadi Nugroho J.: Prakiraan Bisnis, Penerbit Prenada Media, Bandung, 2003.

2. Adisaputro Gunawan \& Asri Marwan: Anggaran Perusahaan, Penerbit BPFE-YOGYAKARTA, Yogyakarta, 2010.

3. Subagyo Pangestu: Forecasting Konsep dan Aplikasi, Penerbit BPFEYOGYAKARTA, Yogyakarta, 1986.

4. Aritonang Lerbin: Peramalan Bisnis, PenerbitGhalia Indonesia, Jakarta, 2002.

5. Hutahaean Chrystoper, Rusmilawati, dkk: Analisis perkembangan jumlah pelanggan terhadap produk Telkom Speedy multispeed pada PT. Telkom di Samarinda, 2012

6. Wulandari Klara: Sistem informasi peramalan penjualan roti pada toko roti baker menggunakan metode exponential smoothing, 2012.
7. Raharja Alda: Penerapan metode exponential smoothing untuk peramalan penggunaan waktu telepon di PT Telkomsel Divre3 Surabaya, 2012.

8. http://vebyenandes.wordpress.com/, Makalah Manajemen Industri: Metode Peramalan (Forecasting), tanggal akses 30 Januari 2014

9. http://purwasuka.web.id/, Mengenal Teori Penjualan, tanggal akses 30 Januari 2014

10. http://telkomspeedy.com/productdescription/, Produk Telkom Speedy, tanggal akses 5 Februari 2014 